\title{
Differences in the Amount of Fluoride Release among Fluoride-Releasing Cements
}

\author{
${ }^{1}$ Koichiro Ogami, ${ }^{2}$ Mituhiro Yokomoto, ${ }^{3}$ Takashi Koike, ${ }^{4}$ Takayuki Ueda, ${ }^{5}$ Kyoko Tomura, ${ }^{6}$ Kaoru Sakurai
}

\begin{abstract}
Purpose: The abutment teeth of removable partial dentures are susceptible to root surface caries and secondary caries, and such caries sometimes result in crown destruction. In particular, in aged patients, this risk increases due to age-associated gingival recession, periodontal disease, decreased amount of saliva, and inadequate brushing caused by decreased finger motor function. Fluoride-releasing materials may prevent such caries. In this study, we evaluated the amounts of fluoride release from various fluoride-releasing cements based on the amount of fluoride release into artificial saliva.
\end{abstract}

Materials and methods: In this study, the following three types of cement were used: Vitremer 2 Paste (3M Health Care: V2 hereafter) and Fuji Luting EX (GC: EX hereafter) as resin-modified glass-ionomer cements, and Clearfil SA Luting (Kuraray Medical: SA hereafter) as a fluoride-containing adhesive resin cement. Using the method indicated by the manufactures, 5 samples (diameter, $8 \mathrm{~mm}$; thickness, $2 \mathrm{~mm}$ ) for each type of cement were prepared. The samples were immersed in artificial saliva $(5 \mathrm{ml})$ and left at room temperature. The artificial saliva used for immersion was replaced every 24 hours until 14 days after the initiation of immersion and every 48 hours thereafter until after 30 days. Fluoride release was measured in the immersion solution using a combination fluoride ion-selective electrode connected to an ion analyzer. For statistical analysis, one-way analysis of variance and the Bonferroni test were performed to compare the amount of fluoride ion release among the groups $(\alpha=0.05)$.

Results: The cumulative amount of fluoride ion release 30 days after the initiation of immersion was the highest for V2 (363.6 \pm $\left.87.1 \mu \mathrm{g} / \mathrm{mm}^{2}\right)$, followed in order by EX $\left(115.6 \pm 7.9 \mu \mathrm{g} / \mathrm{mm}^{2}\right)$ and $\mathrm{SA}\left(57.4 \pm 23.9 \mu \mathrm{g} / \mathrm{mm}^{2}\right)$. Significant differences were observed even from 1 day after the initiation of immersion between V2 and EX as well as SA. Concerning daily changes, the amount of fluoride ion release after 1 day was the highest for each type of cement; it was the highest for $V 2\left(89.8 \pm 13.5 \mu \mathrm{g} / \mathrm{mm}^{2}\right)$, followed by SA $\left(35.9 \pm 8.3 \mu \mathrm{g} / \mathrm{mm}^{2}\right)$ and EX $(34.3 \pm 3.2 \mu \mathrm{g} /$ $\mathrm{mm}^{2}$ ). The amount of release gradually decreased after 2 days or more. Significant differences were observed from 1 day after the initiation of immersion between V2 and EX as well as SA.

\footnotetext{
${ }^{1}$ Senior Assistant Professor, ${ }^{2}$ Resident, ${ }^{3}$ Assistant Professor ${ }^{4}$ Associate Professor, ${ }^{5}$ General Specialist

${ }^{6}$ Professor and Chair

${ }^{1-6}$ Department of Removable Prosthodontics and Gerodontology, Tokyo Dental College, Tokyo, Japan
}

Corresponding Author: Koichiro Ogami, Senior Assistant Professor, Department of Removable Prosthodontics and Gerodontology, Tokyo Dental College, Tokyo, Japan, Phone: 0363809201, e-mail: ogami@tdc.ac.jp
A significant difference between EX and SA was present from 2 until 4 days after the initiation of immersion.

Conclusion: V2 as a resin-modified glass-ionomer cement showed the highest amount of fluoride release, indicating continuous sustained fluoride release.

Keywords: Fluoride, Fluoride release, Fluoride-releasing cement, Resin modified glass-ionomer cement, Retainer.

How to cite this article: Ogami $\mathrm{K}$, Yokomoto $\mathrm{M}$, Koike $\mathrm{T}$, Ueda T, Tomura K, Sakurai K. Differences in the Amount of Fluoride Release among Fluoride-Releasing Cements. Int J Prosthodont Restor Dent 2014;4(3):78-81.

Source of support: Nil

Conflict of interest: None

\section{INTRODUCTION}

The abutment teeth of removable partial dentures are susceptible to root surface caries and secondary caries, and such caries sometimes result in crown destruction. In particular, in the aged patients, this risk increases due to aging gingival recession, periodontal disease, decreased amount of saliva, and inadequate brushing caused by hypanakinesis of the fingers. Longitudinal recall of over denture patients showed a high incidence of detachment of root caps or attachments. ${ }^{1}$ Therefore, the inhibition of the development of caries using fluoride-releasing materials may be effective for protecting abutment teeth. Studies on the mechanism of caries have shown that caries in the early stage repeat progression and recovery by recalcification. In recent years, fluoride-releasing dental materials for recalcification have become commercially available. In particular, conventional glass-ionomer cements release fluoride in a sustained manner, ${ }^{2,3}$ and have fluoride recharge release function. Sustained diffusion of fluoride ions to the tooth was confirmed to strengthen the tooth quality and inhibit the progression of caries. However, these cements have disadvantages, such as inadequate mechanical strength, inadequate adhesion to the tooth and water sensitivity. Therefore, resin-modified glass-ionomer cements ${ }^{4}$ are obtained by adding a resin component in the matrix component to reduce water sensitivity and improve physical properties, and fluoride-releasing resin cements, in which the monomer itself has a fluoride-releasing ability, have been developed. However, resin-modified glass-ionomer 
cements are considered to inhibit fluoride ion diffusion due to the presence of the resin component in the matrix. As a result, compared with conventional glass-ionomer cements, these cements may release the fluoride lower.

The purpose of this study was to evaluate how much fluorine is released from different cements which have sustained-release properties by comparing the amount of fluorine release in artificial saliva, in order to assess dental caries inhibitory effect fluorine released from various materials with sustained-release properties.

\section{MATERIALS AND METHODS}

In this study, the following three types of cement were used: Vitremer 2 Paste (3M Health Care: V2) and Fuji Luting EX (GC: EX) as resin-modified glass-ionomer cements, and Clearfil SA Luting (Kuraray Medical: SA) as a fluoride-containing adhesive resin cement.

The flow of the study method is shown in Flow Chart 1. First, acrylic ring (diameter, $8 \mathrm{~mm}$; depth, $2 \mathrm{~mm}$ ) was filled with each type of material. Acrylic plates were placed on the top and bottom of the molds, and pressed together. The top and bottom of molds were irradiated with light-irradiation (Jetlite 3000, Morita) for 30 seconds respectively. Subsequently, samples were removed from the molds, and irradiated from the side opposite to the previous irradiation area for 30 seconds. After morphological modification to remove excessive portions, the samples were immersed in $5 \mathrm{ml}$ of $10 \mathrm{mM}$ phosphate buffer $(\mathrm{pH}, 7.0)$ and left at room temperature. The phosphate buffer for immersion was replaced every 24 hours until 14 days after the initiation of immersion and every 48 days thereafter until after 30 days. The amount of fluoride ion release in the solution was measured. Five samples for each type of cement were used.

After addition of $500 \mu \mathrm{l}$ TISAB III (Orion Research) as a total ion strength adjustment buffer to $5 \mathrm{ml}$ of the measurement solution, the amount of fluoride ions in the solution was measured using an a combination fluoride ion-selective electrode (Mode 1960, ${ }^{9}$ Orion Research) connected to an ion analyzer (Model 1290, Orion Research). For statistical analysis, one-way analysis of variance and the Bonferroni test were performed to compare fluoride ion release among the fluoride-releasing cements $(\alpha=0.05)$. SPSS 16.0 for Windows was used as an analysis software package.

\section{RESULTS}

The cumulative amount of fluoride release from each type of fluoride-releasing cement is shown in Graph 1. After immersion for 30 days, the cumulative amount of fluoride release was the highest for V2 $(363.6 \pm 87.1$ $\left.\mu \mathrm{g} / \mathrm{mm}^{2}\right)$, followed in order by EX $\left(115.6 \pm 7.9 \mu \mathrm{g} / \mathrm{mm}^{2}\right)$ and SA $\left(57.4 \pm 23.9 \mu \mathrm{g} / \mathrm{mm}^{2}\right)$. Significant differences were observed from 1 to 30 days after the initiation of

Flow Chart 1: Experimental procedure

Acrylic rings ( $8 \mathrm{~mm}$ inner diameter and $2 \mathrm{~mm}$ depth) were filled with $\mathrm{V} 2$, EX and SA

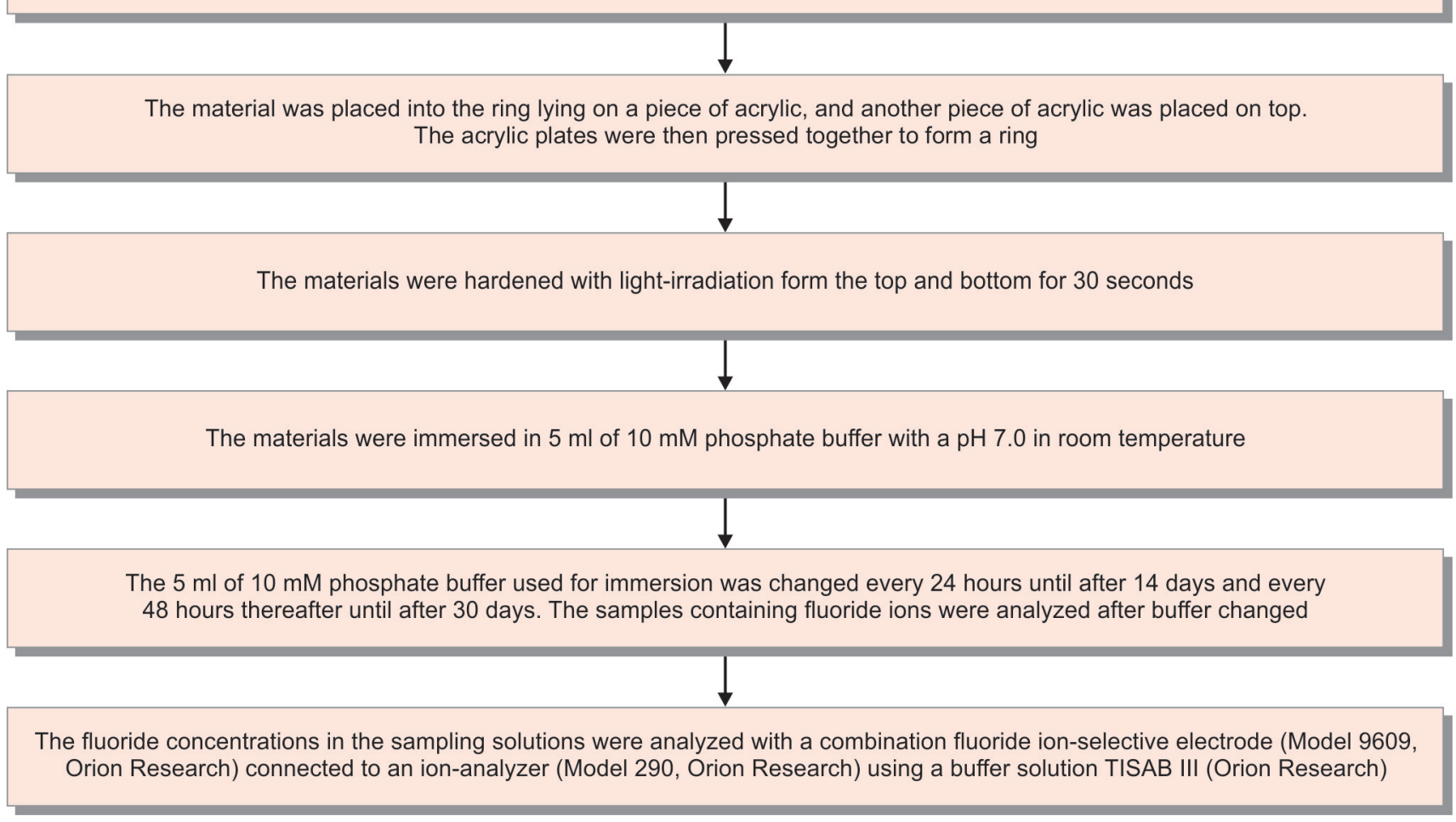




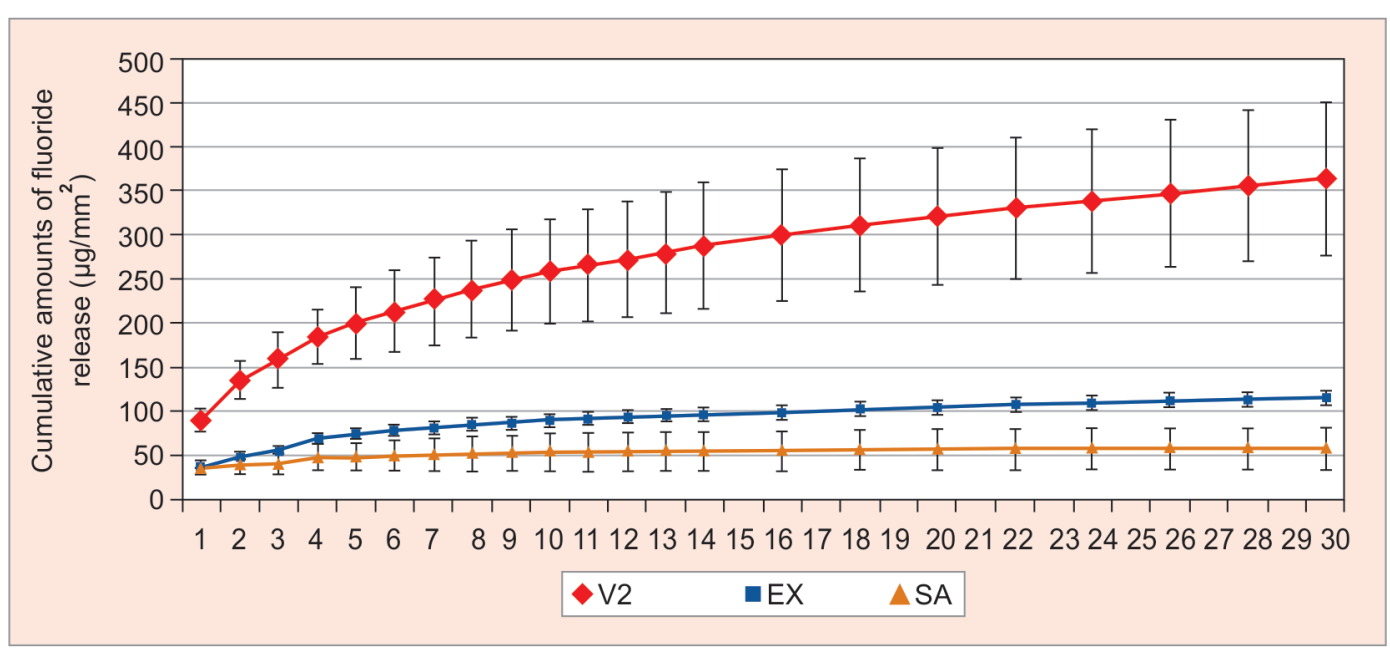

Graph 1: Amounts of cumulative fluoride release from various types of fluoride-releasing cements $(n=5)$

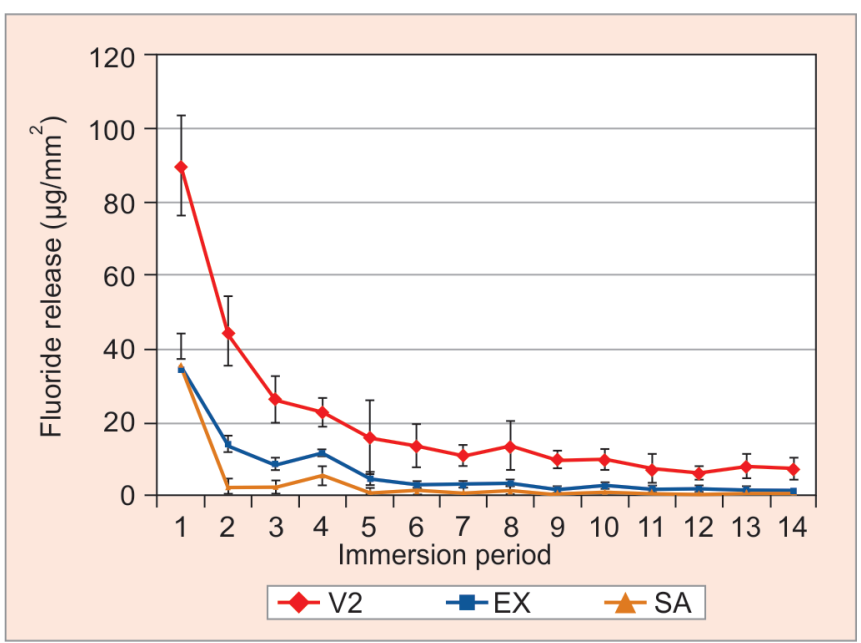

Graph 2: Amounts of fluoride release from various types of fluoride-releasing cements $(n=5)$

immersion between V2 and EX as well as SA. Concerning daily changes (Graph 2), the amount of fluoride release after 1 day was the highest for each type of cement; it was the highest for V2 $\left(89.8 \pm 13.5 \mu \mathrm{g} / \mathrm{mm}^{2}\right)$, followed by SA $\left(35.9 \pm 8.3 \mu \mathrm{g} / \mathrm{mm}^{2}\right)$ and EX $\left(34.3 \pm 3.2 \mu \mathrm{g} / \mathrm{mm}^{2}\right)$. With days, the release amount gradually decreased. Significant diffe-rences were observed from 1 day after the initiation of immersion between V2 and EX as well as SA. A significant difference between EX and SA was observed from 2 until 4 days after the initiation of immersion.

\section{DISCUSSION}

Fluoride is an important factor for improvement in the acid resistance of tooth and recalcification. Fluorides for topical application, such as fluoride-containing toothpastes and mouthwashes are locally used, and do not diffuse in a sustained manner. On the other hand, using fluoride-releasing cements, fluoride diffuses into the adjacent tooth in a sustained manner and is incorporated into tooth. As a result, inhibition of root surface caries and secondary caries in the abutment teeth of removable partial dentures can be expected. In addition, these cements can be recharged with new fluorides, resulting in recovery of their fluoride-releasing ability. Therefore, in this study, the amounts of fluoride ion release from various fluoride-releasing cements were evaluated.

Three types of fluoride-releasing cement were selected for the following reason: V2 and EX as resin-modified glass-ionomer cements, in which the acid-base reaction is supplemented by a light-curing component, and SA as a composite resin, in which a glass ionomer component is present, but its amounts is inadequate for the occurrence of the acid-base reaction, and the acid-base reaction is supplemented by photopolymerization. ${ }^{5}$

There have been many studies in which the amounts of fluoride release from various materials were mesured. ${ }^{6,7}$ In most of them, the materials were immersed in deionized water or distilled water. In this study, used $10 \mathrm{mM}$ phosphate buffer as immersion solution in order to avoid the effects of concentration gradient of fluoride ion in solution on the amount of fluoride release.

A significant difference in the cumulative fluoride ion release was observed between V2 and EX as well as SA from 1 day after the initiation of immersion. Considering that the principle component of all resin-modified glass-ionomer cement powders is fluoroaluminosilicate glass, the difference in the amount of fluoride release is unlikely to be simply due to differences in the fluoride content, and may be associated with resin added as a light-curing component. We speculate that fluoride ions were trapped in the matrix during setting, ${ }^{3}$ and the setting reaction of the resin component preceded the acid-base reaction of the glass-ionomer cement, and a delay in the latter affected fluoride release. In this study, differences in the amount of fluoride ion release were observed, and we speculate that these differences were associated with the setting mechanism, and a higher ratio of resin more markedly reduced the release. A significant 
difference between EX and SA was observed from 2 until 4 days after the initiation of immersion. This may have been because of the following difference. Using the resinmodified glass-ionomer cement, fluoride release was slow due to hydrated silica gel formed on the filler surface after the early setting reaction of fluoroaluminosilicate glass. However, since SA is sodium fluoride, sodium and fluoride ions were directly released.

Concerning daily changes in the amount of fluoride ion release, the amount 1 day after the initiation of immersion was the highest for each type of cement; it was the highest for V2, followed in order by SA and EX. The release gradually decreased with the course after 2 days or more. This is because fluoride ions localized on the superficial layer of cement were released in a sustained manner until after 24 hours as the early cement setting phase using conventional or resin-modified glassionomer cements, resulting in release of many fluoride ions. ${ }^{8,9}$ It has been pointed out that the water absorption of composite resin occurs frequently between filler and matrix, not only in matrix resin. ${ }^{10}$ Due to this, the infiltration of water into the gap between the filler and matrix causes fluorine ions in the interior of the cement to be diffused into the surface layer and released gradually. ${ }^{11}$ It is believed that as a result, those fluorine ions reached a state of equilibrium over time and came to be released at a slow rate.

In many previous studies on fluoride uptake and recharge abilities, conventional glass-ionomer cements were evaluated. Conventional glass-ionomer cements release a great amount of fluoride immediately after filling, but the release decreases with time. However, cements were confirmed to have the ability to recharge attached fluoride. ${ }^{12}$ In this study, the cumulative amount of fluoride release from V2 was the highest. However, the release amount can be increased using methods, such as continuous fluoride gel use and cements, are expected to act as fluoride storehouse in the oral cavity. This may contribute to the prevention of root surface caries or secondary caries of the abutment teeth in the elderly with dentures.

\section{CONCLUSION}

Evaluation of the cumulative amounts of fluoride release from resin-modified glass-ionomer cements (V2 and EX) and composite resin (SA) showed the highest amount of release from V2, followed in order by EX and SA. Concerning daily changes in the amount of fluoride release, the amount 1 day after the initiation of immersion was the highest for each type of cement; it was the highest for V2, followed in order by SA and EX. V2 as a resinmodified glass-ionomer cement showed continuous sustained fluoride release.

\section{REFERENCES}

1. Toolson LB, Taylor TD. A 10-year report of a longitudinal recall of overdenture patients. J Prosthet Dent 1989;62(2): 179-181.

2. Wilson $\mathrm{AD}$, Kent BE. A new translucent cement for dentistry. The glass ionomer cement Br Dent j 1972;132(4):133-135.

3. Dhondt CL, De Maeyer EA, Verbeeck RM. Fluoride release from glass ionomer activated with fluoride solutions. J Dent Res 2001;80(5):1402-1406.

4. Momoi Y, McCabe JF. Fluoride release from light-activated glass ionomer restorative cements. Dent Mater 1993;9(3):151154.

5. McLean JW, Nicholson JW, Wilson AD. Proposed nomenclature for glass-ionomer cements and related materials. Quintessence Int 1994;25(19):587-589.

6. Itota T, Carrick TE, Yoshiyama M, McCabe JF. Fluoride release and recharge in giomer, compomer and resin composites. Dent Materials 2004;20(9):789-795.

7. Verbeeck RM, De Maeyer EA, Marks LA, De Moor RJ, De Witte AM, Trimpeneers LM. Fluoride release process of (resin-modified) glass-ionomer cements versus (polyacidmodified) composite resins. Biomaterials 1998;19(6):509-519.

8. Tam LE, Chan GP, Yim D. In vitro caries inhibition effects by conventional and resin modified glass-ionomer restorations. Oper Dent 1997;22(1):4-14.

9. Attar N, Onen A. Fluoride release and uptake characteristics of aesthetic restorative materials. J Oral Rehabil 2002;29(8):791-798.

10. Söderholm KJ. Degradation of glass filler in experimental composites. J Dent Res 1981;60(11):1867-1875.

11. Eronat N, Kocatas N, Alpöz AR. A comparative study of fluoride uptake from dentin bonding agents and glassionomer cements in permanent and primary tooth enamel. Quintessence Int 1999;30(7):496-500.

12. Freedman R, Diefenderfer KE. Effects of daily fluoride exposures on fluoride release by glass ionomer-based restoratives. Oper Dent 2003;28(2):178-185. 